\title{
Research on Teaching Mode of Broadband Wireless Communication Course Based on the Cooperation of Industry and University
}

\author{
Baofeng $\mathrm{Ji}^{1,2}$, Gaoyuan Zhang ${ }^{1,2}$, Bingbing Xing ${ }^{1}$, Guoqiang Zheng ${ }^{1}$, Hongfeng $\mathrm{Gao}^{1}$ \\ ${ }^{1}$ School of Information Engineering, Henan University of Science and Technology, Luoyang 471023, China \\ ${ }^{2}$ School of Aerospace Institute, University of Electronic Science and Technology of China, Chengdu 611731, China
}

\begin{abstract}
In the electronics and information profession, "Broadband Wireless Communication" is a professional compulsory course, which covers many introductory knowledge in the communications industry and plays a key role in the students' future engagement in the communications industry. In recent years, the 5G/B5G mobile communication technology has achieved rapid development, which has brought tremendous changes in the market, and has made the course increasingly important in communication area. Therefore, it is necessary to develop the course, many colleges and universities are needed to help students integrate the professional knowledge of this course. In order to solve the problems existing in current single-level teaching model in universities, the paper studies the way to integrate the real project of the enterprise, the research project of the teacher and the curriculum teaching of the students, and constructs a new teaching model integrating production, study, and research(PSR).The teaching practice shows that the use of a model based on the integration of production, study and research for teaching and learning has a significant effect on improving the professional knowledge ability of undergraduates majoring in electronics and communications, and is expected to cultivate a group of outstanding applied research and professional technicians.
\end{abstract}

Keywords-The integration of Industry and university; Wireless communication; Teaching mode; Cultivation method

\section{INTRODUCTION}

Broadband wireless communication course is a specialized course for undergraduate students of telecommunications. It is one of the main courses of telecommunications professional courses such as communication principles and digital signal processing, and it is a specialty course of the university's electronic information specialty. Broadband wireless communication aims to train telecommunication students who have studied communication principles and computer communication network knowledge to help them master key communication technologies at the forefront of information subjects, keep abreast of the latest developments in the world, and strengthen theoretical and practical learning. Methods to develop their ability to analyze and handle complex engineering problems using the theoretical knowledge they have learned [1-2].

Broadband wireless communication courses closely follow the development pace of global mobile communications, and pay attention to the development of key technologies for next- generation mobile communication $\mathrm{B} 4 \mathrm{G} / 5 \mathrm{G}$,focusing on multiaccess, interference management, networking technology, antijamming technology, capacity enhancement and other technical basic principles. Combining theoretical guidance with experimental practice to develop students' operational and creative capabilities. Broadband wireless communication course is a professional course in the direction of telecommunications. It is adapted to the needs of the rapid development of modern social communication and enables students to have a deeper understanding of the principles of mobile communication, digital mobile communication systems and personal communication, and become highly qualified skills. Talented people will enter the society after graduation to participate in the work and increase the competitiveness of their employment to lay a solid foundation. This course mainly studies wireless communication, mobile communication and Internet, wireless access technology, wireless LAN, WAP technology, wireless paging, telephone and Internet, Bluetooth technology, etc. After studying this course, students are required to learn from the computer network system. All aspects of composition, networking, and applications understand and master newer networking and wireless communication technologies.

As a major extension course of electronic information, the teaching characteristics of broadband wireless communication mainly include the following aspects:

- The course system is complete. While teaching the theoretical system of broadband wireless communication, the theory methods of communication theory, digital signal processing, and computer communication networks are also used in the analysis and research of broadband wireless communication. Taking the high-speed and reliable transmission of signals as the entry point, the theory methods of the modern communication theories, digital signal processing, signals and systems and other subdisciplines are integrated to help students form a complete knowledge network with a communication direction.

- Basic training is solid. Emphasis on basic theory, application of the latest scientific research results, use of modern science knowledge such as thinking, systems theory, logic, research to promote teaching and research, teaching reform and teaching, large-scale improvement 
in teaching quality, fully embodies teaching and scientific research, engineering applications and curriculum learning 5 integrated teaching model. This course strengthens students' ability to use hands-on operations, the ability of theoretical knowledge to communicate in experimental systems, and the ability to innovate in experimental design programs.

- Practice is in place. This course not only has profound and cutting-edge basic theoretical knowledge, but also has a complete experimental design analysis and processing practice, and it also combines relevant electronic design competitions, smart cars and other competitions, and has a very good application prospect.

- The tightness of the combination of teaching and the latest technology in the enterprise. As a professional course in electronic information, the course has a close relationship with the current global electronics design, experimental system development, new technology research and development, whether it is the basic theoretical knowledge required for the latest technological development of the enterprise, or the much-needed embedded development, R\&D of mobile communications, and the realization of the Internet of Things all play a complementary role in cultivating much-needed talent in the era. In recent years, the author's teaching team has adopted the $3+1$ curriculum reform mechanism to enable telecommunications students to become advanced application research professionals required by related companies through internships, practical training and other training.

\section{THE NECESSITY OF PSR}

\section{A. The fast development, difficult materials selection and so on}

Mobile communications technology is developing at an alarming rate. From the 1980 s to the present day, the mobile communication system has evolved from the original second generation mobile communication technology $(2 \mathrm{G})$, which was based on digital digital voice transmission technology, across the middle third and fourth generations mobile communication technology, and then to the fifth generation of mobile communications technology $(5 \mathrm{G})$.Teachers who taught this course a few years ago need only teach $2 \mathrm{G}$, 3G, or 4G.However, as the $5 \mathrm{G}$ era is approaching, the $5 \mathrm{G}$ mobile communication system is also one of the important learning systems. Due to the rapid development of the communications industry in recent years, each generation of mobile communications technology has its own unique new technologies, more and more content, and more complex. At present, the update rate of the course materials is far lower than that of the mobile communication technology, which makes the students' knowledge lag behind. And with the gradual enrichment of content, completing such a large number of teaching tasks within the existing class hours is a bit laborious. In the teaching process, students not only need to learn the basic knowledge of communication and related technologies, but also need to learn the network structure and key technologies of each system [3]. Therefore, learning this course is a great challenge for students and teachers.

\section{B. Monotonous teaching methods and strategy}

At present, most of the courses use traditional teaching methods. Teachers give lectures and students learn more passively. This course generally adopts the form of "multimedia + board" for "hearing and listening" teaching. Teachers perform teaching according to PPT, and the time for students to discuss and think is small, which is not conducive to the divergence of students' thinking activities. Because the teaching content of the course is more knowledgeable, it is boring. Some technical knowledge involved in mobile communication can only be understood by students through the teaching of theoretical knowledge and cannot be combined with practical applications. The content of the book is biased towards basics, and it is less relevant to the content of the actual job. Students are in school for a long time and have few opportunities to socialize outside, and they cannot know where to study and see the learning effect in the learning process. Therefore, it is difficult for students to truly connect with market demands [4].Such learning is blind, and it is unfavorable for the future to enter the society. Adopting such a single teaching model makes students' interest in learning less, and teaching results will be poor. Therefore, teaching using the traditional teaching model alone cannot meet and satisfy the teaching of the course.

\section{The slow update speed of experimental equipment}

Due to the rapid development of the mobile communications industry, the speed of the update of wireless communication technology has been difficult to quickly land on textbooks. At the same time, the related equipment of wireless communication is relatively expensive, and it is difficult for the general colleges and universities to meet the experimental needs of students. Moreover, the replacement of teaching equipment in schools is generally unsatisfactory, and many factors will lead to a decline in student's ability to work, which will directly affect the quality of courses and experimental teaching [5].

Due to many reasons, using the traditional teaching mode can no longer meet the requirements of rapid development of wireless communication courses and experimental teaching. Therefore, adopting cooperation with related companies for production, learning, and research can not only enable students to put the latest professional knowledge they learned into practice, but also effectively train students' hands-on abilities, achieve better learning results, and can also ease financial constraints. 


\section{THE NEW TEACHING MODE BASED ON PSR}

- Broadband wireless communication courses can adopt different teaching methods for different teaching contents in different teaching stages. The basic theory part adopts the teaching method. It not only pays attention to the basic knowledge, but also lays a solid foundation for the students. It also appropriately introduces academic frontiers and different academic viewpoints to arouse students' professional interest and cultivate their independent thinking qualities. In the teaching, full use is made of multimedia means, through the animation demonstration to describe the signal transmission process of the transmitter and receiver and other knowledge, to establish a more intuitive wireless space concept, through the appropriate formula derivation, so that students understand the application of mathematics and other basic knowledge.

- The professional skills section uses a combination of theoretical teaching and practical operations. It teaches how to apply theoretical knowledge to experimental communication and organizes team competitions and discussions so that students can consolidate and deepen their understanding of what they have learned.

- Using diversified teaching methods and teaching methods, teachers should adopt different teaching methods and methods according to different teaching contents in the teaching process. For example, for the explanation of the basic principles, because of the relatively large amount of knowledge involved, it is difficult for the students themselves to form a system by coherent knowledge. Teachers use induction to classify the knowledge and summarize and compare related knowledge points. For some of the more abstract, students can not understand and feel boring knowledge points, can be described by the demonstration method. For example, the multiple access method can be compared to the exchange between different languages, to present the knowledge to be learned more vividly and to obtain better teaching results.

- Strengthen the construction of virtual experimental platform, through the establishment of a virtual experimental platform, combined with theoretical knowledge, the introduction of some applications in the project, combined with the development needs of social talent. At the same time, it reduces equipment investment, saves a lot of resources, facilitates teachers to lay out experimental tasks, checks students to complete experiments, and facilitates students to conduct experiments anytime, anywhere, without being confined to the laboratory. For example, to explain the chaotic modulation method in secure communication, the simulation program can be analyzed and the simulation results are shown in Figure 1.

- The engineering project teaching method and project teaching method are based on the theory of cognitive assimilation. It is a practical teaching method that is commonly used in some developed countries. In the project teaching method, teachers and students conduct teaching activities by jointly implementing a complete project work. It has the characteristics of practicality, autonomy, development, comprehensiveness, and openness. In 2001, the Massachusetts Institute of Technology and the Chalmers Institute of Technology in Sweden, Linkoping University, and the Royal Institute of Technology jointly proposed the CDIO project education philosophy and implementation system [6-7]. This course is mainly carried out in cooperation with Beijing BaikeRongchuang to achieve the reform and exploration of curriculum teaching, experimental teaching and curriculum design, and achieved good results.

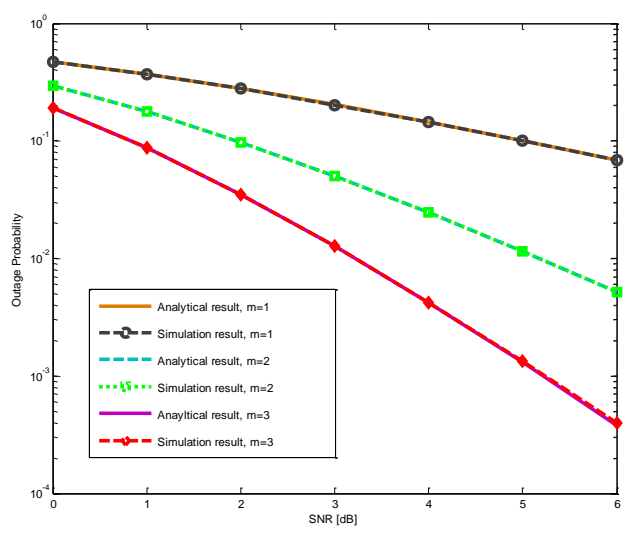

Fig. 1. Analysis of Bit Error Rate Performance of Wireless Communication System

\section{CONCLUSION}

In this paper, aiming at the problems existing in the singlemode teaching mode and lack of experimental teaching in the current "Broadband Wireless Communication" course, the teaching and experimental modes of integrating production, learning and research with the course-related companies are proposed, effectively embodying the 5 integration and $3+1$ teaching mechanisms. It studies how to integrate the real project of the enterprise, the research project of the teacher and the curriculum teaching of the students, and builds a new model of teaching in the integration of production, study and research. In recent years, teaching practice has shown that the use of a model based on the integration of production, study, and research for teaching and learning of courses has a significant effect on improving the professional knowledge ability of undergraduates majoring in electronics and communications. 


\section{ACKNOWLEDGMENT}

V: Dr. Baofeng Ji received the Ph.D. degree in information and communication engineering from Southeast University in 2014, China. Since 2014 he has been a post-doctorial fellow in the School of Information Science and Engineering, Southeast University, China, now he also is an association professor in Henan University of Science and Technology. His current research interests include MIMO wireless communications, cooperative wireless communications and millimeter wave wireless communications.

Funds: National Natural Science Foundation of China under Grant U1404615, 61671144 and 41605122; National Thirteen Five National Defense Fund under Grant 61403110302; Project of Education Department Cooperation Cultivation under Grant 201602011005; China Postdoctoral Science Foundation under Grant 2015M571637.

\section{REFERENCES}

[1] Juan Zheng, Sunyu Wang. Discussion on the accreditation system of master level engineering education in Britain [J]. Research on Higher Engineering Education, 2015, 1:83-90. (In Chinese)

[2] Baofeng Ji, Sudan Chen, Guoqiang Zheng. Research on professional authentication methods of information and Communication Engineering [J]. Technology Wind, 2016, 3:92-93. (In Chinese)

[3] Xiangqing Zhu, Xingping Zhang, Guiming Liao. Research and Exploration on Practical Teaching of Communication Engineering Principle Project Engineering [J]. Journal of Jiaying University, 2014, 32(12):84-88. (In Chinese)

[4] Jing Chen. Exploration and Practical Research of Graduation Design Pattern Based on the Integration of Production, Teaching and Research [J]. Software Guide Education Technology, 2016, 15(8):73-74. (In Chinese)

[5] Ping Yang, Damin Zhang, Guomin Liu. Discussion on the Training Model of Professional Degree Graduates in the Field of Electronics and Communication Engineering [J]. Software Guide Education Technology, 2016, 15(4):34-35. (In Chinese)

[6] AWLEY E. F., Malmqvist J., Ostlund S., et al. Rethinking Engineering Education-The CDIO Approach [M]. New York: Springer, 2007. (In Chinese)

[7] Peihua Gu, Minfen Shen, Shengping Li. Exploration of Engineering Education and Talent Training Models from CDIO to EIP-CDIO Shantou University [J]. Research on Higher Engineering Education, 2008, 26(1):12-20. (In Chinese) 